\title{
تأثير استخدام البطاقة في تعليم مهارة القراءة (بحث تجريبي)
}

\section{Selvia Nelis}

Institut Agama Islam Yasni Bungo

Email: selvianelis09@gmail.com

\section{تجريد}

المشكلة الأساسية في هذه الرسالة: كيف كان تأثير استخدام البطاقة في تعليم مهارة القراءة. ومنهج

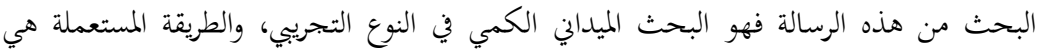

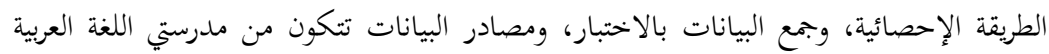

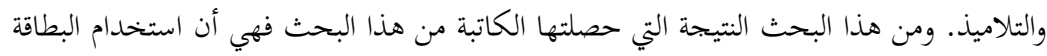

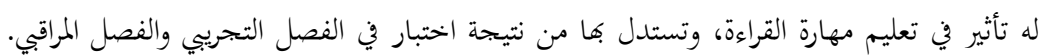

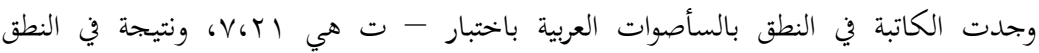

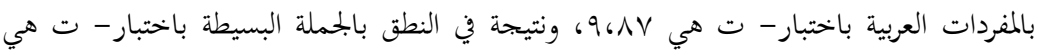

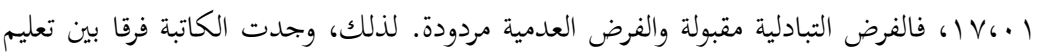

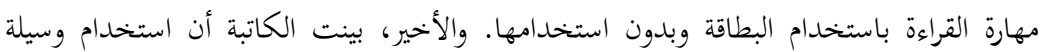

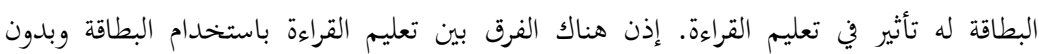

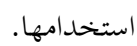
مفتاحه: البطاقة, وتعليم, ومهارة القراءة

\begin{abstract}
Abstrak
Masalah pada penelitian ini yaitu Bagaimana pengaruh penggunaan kartu pada pembelajaran keterampilan membaca. Metodologi penelitian adalah penelitian lapangan yang berbentuk kuantitatif jenis eksperimen yang digunakan adalah metode statistic pengumpulan data dengan tes, dan sumber
\end{abstract}

Nur EI-Islam, Volume 7, Nomor 1, April 2020 
Selvia Nelis

data yang terdiri dari guru bahasa arab dan siswa. Dan hasil penelitian yang diperoleh penulis adalah bahwa terdapat pengaruh penggunaan kartu terhadap pembelajaran keterampilan membaca, dapat diketahui dari hasil tes pada kelas eksperimental dan kelas kontrol. Penulis menemukan pengucapan dengan T-test adalah 21,21, dan hasil pada pengucapan kosa kata dengan T-test adalah 9,87, sedangkan hasil pada keseluruhannya dari T-test adalah 17,01 . Oleh karena itu penulis menemukan perbedaan antara keterampilan membaca menggunakan kartu dan tanpa menggunakan kartu. Dan dapat disimpulkan bahwa penggunaan kartu berpengaruh terhadap pembelajaran kemahiran membaca. Jadi ada perbedaan antara pembelajaran membaca menggunakan kartu dan tanpa menggunakan kartu.

Kata Kunci: Kartu, Pembelajaran, Kemahiran membaca

مقدمة

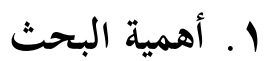

تعليم اللغـة العربية هي عملية تربوية تهدف إلى الدفع والإرشاد والتطوير في بناء قدرة اللغة العربية الصحيحة إيجابية كانت أو سلبية. الغرض من تعليم اللغة العربية لتطوير المهارات الأربعة هي مهارة الاستماع، مهارة الكالام، مهارة القراءة، ومهارة الكتابة. وهذه المهارات أعمال مرتبة أو منظمة في عملية تعليم اللغة العربية.

يهـدف تعليم اللغـات بصفة عامـة إلى اكتساب الدارسـين بحموعـة مـن المهارات

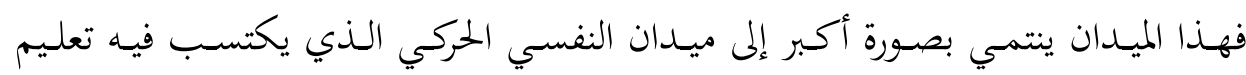
المهارات مكانة خاصـة. والمهارة اللغوية هي أبسط وحدات النشاط اللغوى الذى يؤدى أداء صسحيحا وجيـا في أقل زمسن مـكن، ويتصسل بـأى بحـال مـن بحـالات الاستماع

'رشدي أحمد طعيمة، دليل عمل في اعداد المواد التعليمية لبرامج تعليم العبية، (المكة المكرمة: المعهد

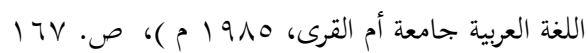


listening، والكلام speaking، والقراءة writing وتنقسم هذه المهارات إلى قسمين، (1) مهارة سلبية (pasif) وهي مهارة الإستمع والقراءة لأن

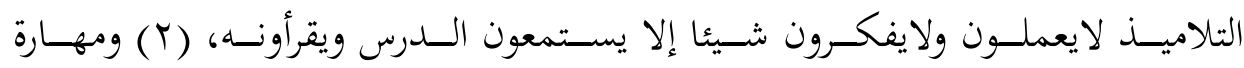

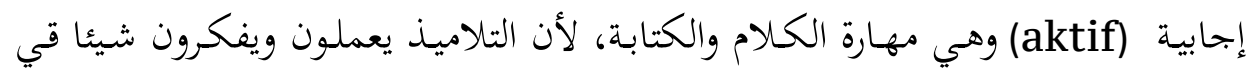
عملية التعليم، وهم يتكلون ويكتبون. وهذه الخصائص تدل على أن تعليم اللغة العربية يحتاج إلى طرق مناسبة ومدرس اللغة الماهر والفـاهم عن علم اللغة وكيفية ايصال المواد

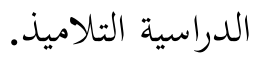

إذن مهارة القـراءة مـن أهـم المهارات اللغويـة، القـراءة بحعل التلاميذ أن يلفظوا

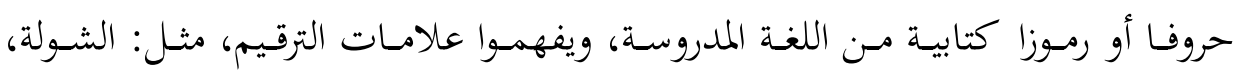

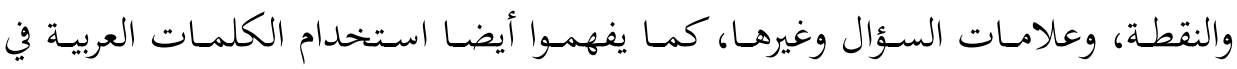
النصوص وتراكيبها ومعاها المقروءة. هناك عدة أهميات في القراءة كما قال عبد القادر احمد: القراءة أهم مـادة مـن المواد الدراسية لصلتها بكل مـادة أخـرى. والتلاميذ الذى يتفوق فيها يتفوق في المواد

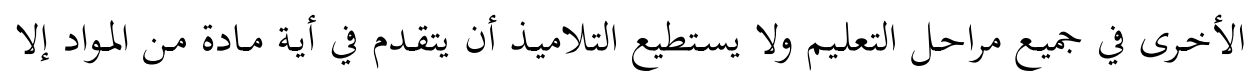
إذا ستطاع السيطرة على مهارة القراءة وهى أعظم وسيلة موصلة إلى الغاية المطلوبة من

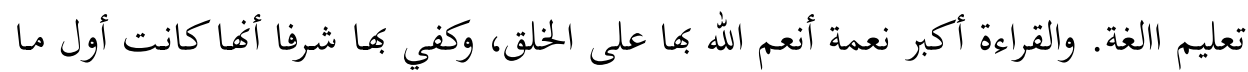

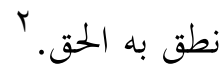

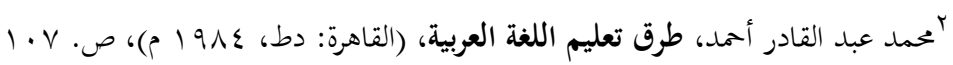


Selvia Nelis

وكذلك مهـارة القـراءة مهمـة جــا لأن بمهـارة القـراءة أن يسـتطيع التلاميـذ فهـم

المقروء وفهـم النصوص العربي. اذا قرأ التلاميـ الشيء المقـروء لابــ لهـم أن تفهمـواعن المقـروء، اذا لا تفهمـون فـلا يحصـل الأهـداف على مهـارة القـراءة. "تقــدم تطوير العلـوم تطلب الطلبة أن تطور مهارات اللغة، وفي محأولة لتحسين نوعية التعليم من خحلال عملية التعليم. في الحقيقـة أسـاس عمليـة التعليم هـو نظام، وفيـه مختلف العمل معـا ومتكاملـة لغـرض التعليم. مـن تلـك المكونـات هي هـدف مـن التعليم، المعلمــين والمتعلمــن، المـواد التعليمية، وطرق التعليم واسترابتيات التعليم، أدوات أو وسائل التعليم والتقييم". ب لذلك لابـد على الملدرس أن يستخدم وسـائل التعليم المناسـب في تعليم مهارة القرأة، لأن استخدام وسائل التعليم المناسب يجصل على أغراض التعليم الكافية والكاملة ثم يبعـث رغبـة ودافع التلاميـذ لتعليم اللغـة العربيـة. وهـذه الآراء مناسـب بقـول حاملكك (Hamalik) أن استخدام الوسائل في التعليم يبعث رغبـة في إثارة الاهتمام جديدة، ودافع وتشجيع أنشطة التعلم حستى تـأثر على الطـلاب في النفسي. وقـال إبـراهيم أن وسائل التعلم تحجليب السرور للتلاميذ وبحدّد نشاطهم وأنها تساعد (Ibrahim) علي تثبيت الحقائق في أذهان التلاميذ وأنها تحيي الدرس. ؛ الوسيلة التي تناسب بتطوير الزمان والأدوات الأنشطة المتفرحة في منهاج مادة علوم الطبيعة والحياة في تعليم القراءة هي وسيلة البطاقة، لأن وسيلة البطاقة إحدى من وسائل بصرية التى تساعد مدرسا في تعليم مهارة القراءة. لذلك لابد على المدرس اللغة

Abdul Halim Hanafi، Perencanaan Sistem Pengajaran Bahasa Arab، (Batusangkar: STAIN Batusngkar، 2003)، h. 48

Azhar Arsyad، Media Pembelajaran،( Jakarta: PT Raja Grafindo Persada 2005)، ed. 1. Cet. 6. hal. 15 
العربية يستخدم وسائل البطاقة في تعليم مهارة القرأة كمثل استخدام وسيلة البطاقة الأسئلة أو الإجابة تساعد التلاميذ في تركيب الجملة لتكوين مفردات أو كلمة. كما قال

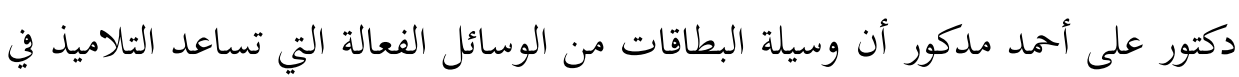

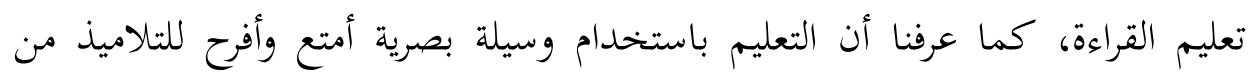
استخدام وسيلة سمعية. لأن المدرس يستعمل الوسائل غير الممتعة في تعليم مهارة القراءة

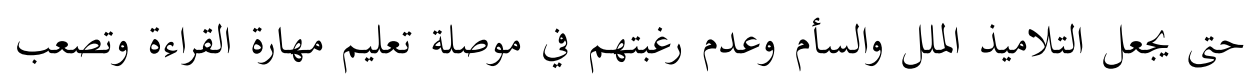
التلاميذ في تدريب مهارة القراءة.

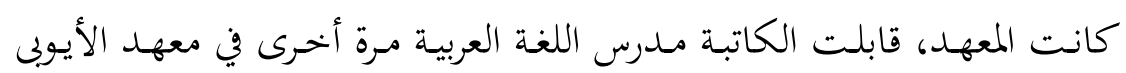

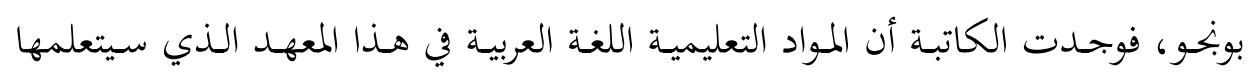
التلاميذ ع حصة X X · ع دقيقة بالقائين في كل أسبوع. أمـا أغراض تعليم اللغة العربية

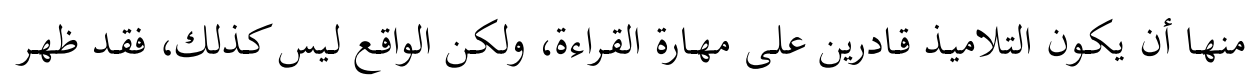

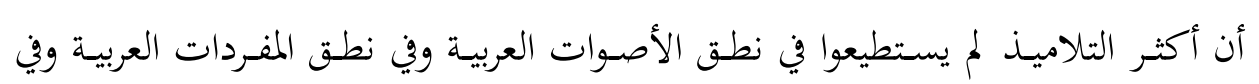
نطق الجملة البسيطة. كذلك من أهداف مهارة القراءة في معهد الأيوبى بوبخو .

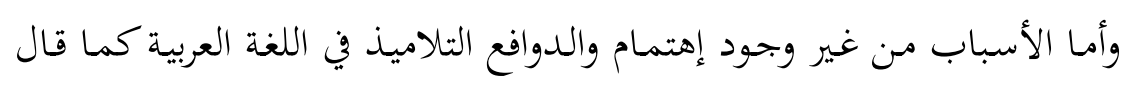

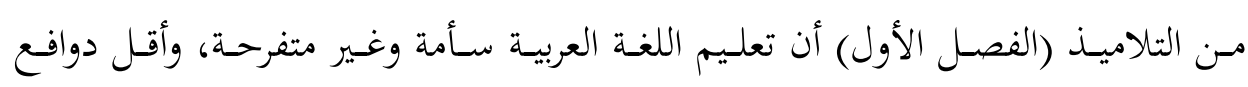

• صلاح عبد البجيد العربي، تعلّم اللغات الحية وتعليمها بين النظرية والتطبيق، (القاهرة: مكتبة

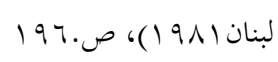
" مقابلة بين الكاتبة والمدرس اللغة العربية في معهد الطوالب غونونج بادنج بانخج يوم الاثنين فن التاريخ ع

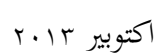


المدرس في غرض التعليم التلاميذ. لوقال مـدرس اللغة العربية أن أقل وسائل الدرس في

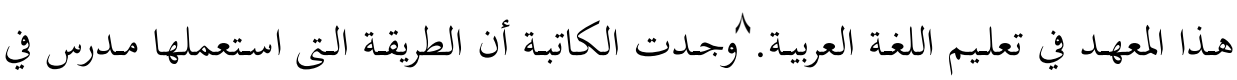
تعليم اللغة العربية في مهارة القراءة هى الطريقة التقليدية، استخدام المدرس الوسائل منها كتاب اللغة العربية واستخدام السبورة فقط، والوسائل التى استعملها مدرس هي الوسائل غير الممتعة في تعليم مهارة القراءة حتى يجعل التلاميذ الملل والسأم وعدم رغبتهم في تعليم

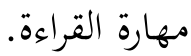

وبعد مـا قابلت الكاتبة مع معلم اللغة العربية في هذا المعهد، تبين لها أن هذه الأهداف لا يتحقق كما هو المرجو. وذلك بنظر إلى نتيجة الاختبار اليومي للتلاميذ في

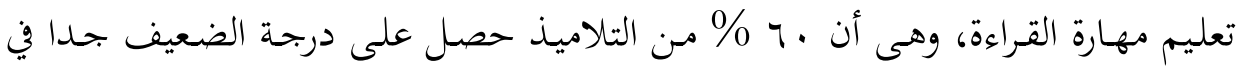

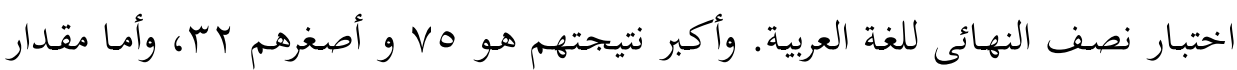
نتيجة تعليم اللغة العربية هو • V.

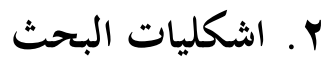

من خلفية البحث السابقة فالمسألة الأساسية في هذا البحث وهي كيف كان تأثير استخدام البطاقة في تعليم مهارة القراءة (بحث تحريبي).

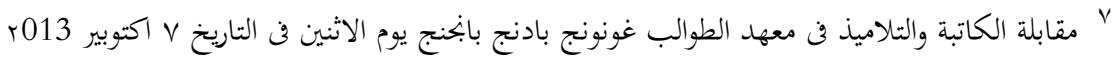

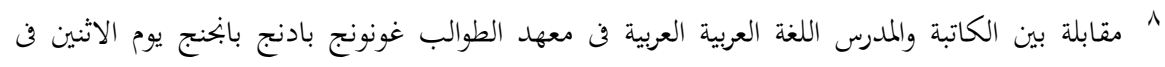

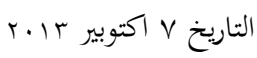




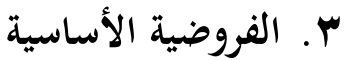

الفروضية الأساسية هي استخدام البطاقة له تأثير في تعليم القراءة في معهد

الأيوبى بونجو Ha (فرض تبادلية).

أ. أل الإطار النظري

يتناول الفصل الثاني إطارا نظريا وتبين الكاتبة فيه ثلاثة مباحث، هي المبحث

الأول عن مهارة القراءة، والمبحث الثاني عن وسيلة البطاقة في تعليم اللغة العربية،

والمبحث الثالث عن فرض البحث.

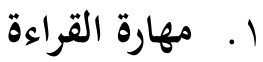

مهارة القراة هي مهارة من المهارات المهمة التى تجب على متعلم اللغة الأجنبية

أن يتعلمها وهي ترتبط ارتباطا وثيقا بالكلام والكتابة. أن مهارة القراءة في الرموز الكتابية

وتحويلها إلى أصوات منظومة وهي مهارة تلعب فيها الخيرات السابقة للمتعلم دورا كبيرا في

إتقاها. "مهارة القراءة هي القدرة على التعرف والفهم محتويات شيئا كتبه قراءة في قلبي. القراءة هى تحويل النظام اللغوي من الرموز المرئية (الحروف) إلى مدلولاته. وهذا يعني أن إنسي

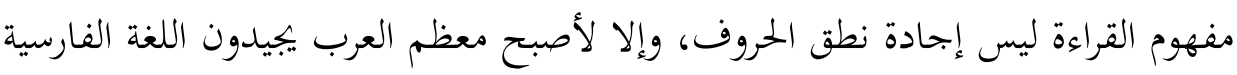

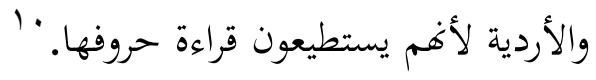

'Acep Hermawan, Metodologi Pembelajaran Bahasa Arab, (Bandung: Remaja Rosda Karya, 2011), h. 143

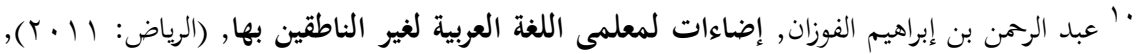


Selvia Nelis

ولقد يعتقد بعض الناس أن القراءة هى قراءة الكلمات على الصفحة المطبوعة أو المكتوبة، واستحضار المعنى الذي يريده المؤلف، وإذا تقبل المدرسون هذه التعريف، وعملوا التلاميذ طبقا له فسوف تفقد الأجيال الناشئة القدرة على النقد والتقويم. أن القراءة في وضعها الحقيقى تشمل كلا من التعرف على الكلمات وتحصيل تفكير الكاتب.'إذذن مهارة القراءة هي القدرة على قراءة النصوص العربية أو الكتب المكتوبة باللغة العربية جيدا وفصيحا وتشمل التعرف على الرمز اللغوى والفهم ولقد إلى هذا الفهم الجحديد لعملية القراءة عوامل نفسية واجتماعية.

وتنقسم القراءة من حيث الأداء قراءة صامتة، وقراءة جهرية. كما تنقسم من حيث الغرض من القراءة إلى قراءة للدرس والبحث، وقراءة للاستماع، وقراءة لحل المشكلات، وسوف نعرض لكل نوع من هذين النوعين بالتفصيل فيما يلي: أ) القراءة الصامتة

\section{ب) القراءة الجهرية}

وهذه الطريقة على تعليم القراءة حسب المراحل الاتية: أ) يحفظ المتعلم كل حرف والصوت اللغوي الذى يقابله ب) يردد المتعلم مقاطع من كلمات تحوى الحروف التى يبق له تعلمها بحيث يشمل كل مقطع حرفا ساكنا واخلر متحركا مثل:

$$
\text { با.......بي......بو }
$$

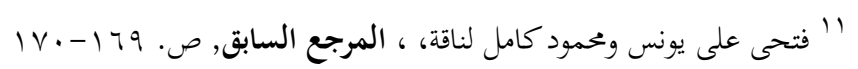


ج) يبدا المعلم في ممارسة قراءة كلمات ختوى على حروف يسهل نطقها ويتكرر بعضها اكثر من مرة في نفس الكلمة مثل: باب

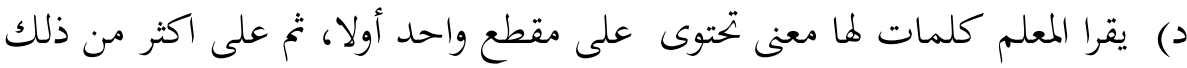
تدريجيا حتى يتقن قراءة الكلمات.

هـ) يجري تمرين المتعلم على قراءة عبارات قصيرة تتكون من كلمات مألوفة، ثم قراءة

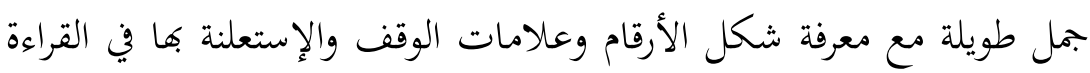

$$
\text { الجهرية. }
$$

من البيان السابق، هذه الطريقة تساعد المتعلم على التعرف على الكلمات التى سبق له المران عليها، وأن معرفته بنطق الحروف في اللغة الأجنبية بتعله قادرا على قراءة الكلمات لم يسبق له التعرض لها، وأنه عادة يتقن مهارة الهجاء بعد ذلك لأنه بدأ يتعلم الحروف التى تتكون منها الكلمات.

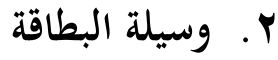

البطاقة هي قطعة من قطعة الورق المقوى يكتب على كل منها عبارة أو كلمة أو

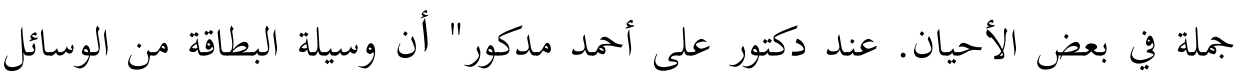
الفعالة التي تساعد التلاميذ في تعليم القراءة والكتابة، وذلك من خلال مواقف وأنشطة فعالة، ومشوقة". أما البطاقة التعليمية هي بطاقة تربوية، حققت أهداف جليلة الأثر في الحقل التعليمي، وأدت رسالة من اسمي الرسالات حين جائت مفتاحا للقراءة والمعرفة. كان رأي بعض المربين عن تقسيم الوسائل إلى ثلاثة أقسام:

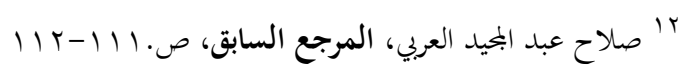


Selvia Nelis

أ) وسائل سمعية، مثل الإذاعة وأجهزة التسجيل والوسائل اللغوية. ب) وسائل بصرية، مثل السبورة، البطاقة، وذوات الأشياء المدروسة ونماذجها وصورها والبطاقة والرسوم والمصورات.

ج) ومائل سمعية بصرية، مثل والتليفيزيون والفانوس السحرى، مصجوبا بشرح

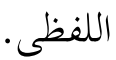

وسيلة البطاقة هى إحدى من وسائل بصرية، كما عرفنا أن الوسائل البصرية أفرح للتلاميذ من الوسائل السمعية بل في تعليم اللغة العربية.

ونوجز فيما يلي فوائد استخدام المعينات البصرية في تعليم اللغة، منها: أ) نتوع المعينات البصرية سير الدرس، فتجعله أكثر حيوية وتشويقا.

ب) تشجع التلميذين على نقل أعينهم من صفحات الكتاب، مما يجعل كلام التلميذين مع زميله أكثر سهولة وأقرب إلى الواقع.

ج) تحد من كلام المدرس في الدرس، وتفسح فرصا أطول للدارس كي يتكلم. فالوقت الذي يقتطع من كلام المدرس، يستفيد به التلميذ في مزيد من التدريب على اللغة.

د) توضح الأمور بتوفير بعد جديد للواقع، وتشرح الحقائق التي يمكن أن تمر مرورا عابرا، دون أن ينتبه إليها التلميذ، فالمعاني المجردة عن الصوت والحرارة والسرعة والحجم والمسافة والوزن واللون والعاطفة يمكن تدريسها بسهولة، وتقريبها إلى أذهان التلميذين بالمعينات البصرية. 
هـ) يجد التلميذ ذو الخيال الخصب ما يتعلمه من لغة سهلا وممتعا، من خلال

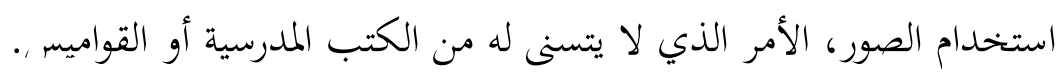

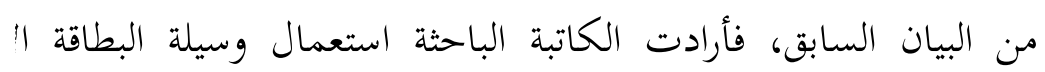

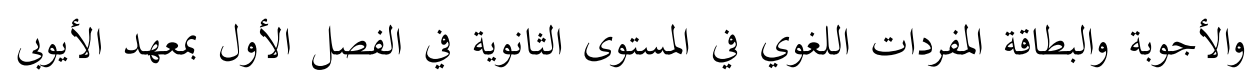
بوبنو.

\section{ج. منهج البحث}

المراد بمنهج البحث في هذه الرسالة هي الخطوات التي تقوم بها الكاتبة للحصول

على أغراض البحث وتحليل المسائل وإجابتها. ويتكون هذا الباب من عدد الفصول.

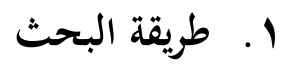

نوع البحث الذي تستعمله الكاتبة في هذه الرسالة فهي البحث الميداني الكمي بالنوع التجريبي، والطريقة المستعملة هي طريقة إحصائية لأن الكاتبة تبحث عن الوسائل البطاقة في تعليم مهارة القراءة فن المستوى الثانوية بمعهد الأيولى بوبكو. أ. بحتمع البحث وعينه

تطلق كلمة بحتمع على جميع الحالات والأفراد والأشياء التي يتجه الباحث

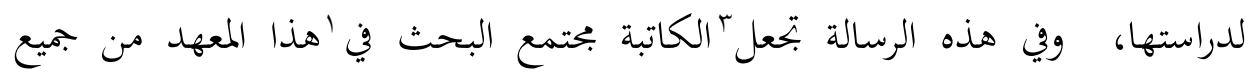

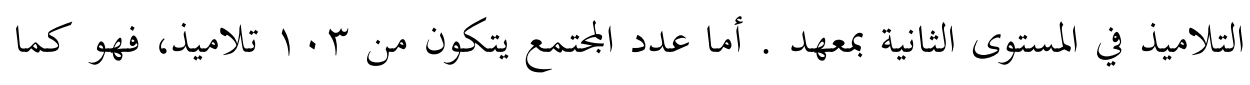

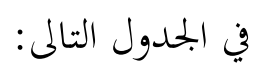

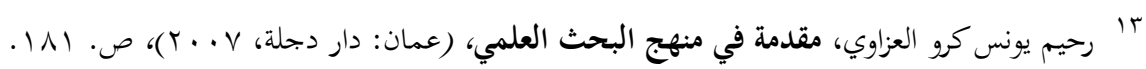


Selvia Nelis

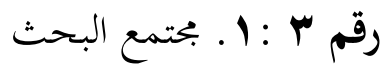

\begin{tabular}{|c|c|c|}
\hline التلاميذ & العناصر & 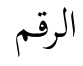 \\
\hline$r$. & التلاميذ في الفصل الأول 1 & 1 \\
\hline$r$. & التلاميذ فن الفصل الأول r & r \\
\hline IV & التلاميذ فن الفصل الثان 1 & r \\
\hline 11 & التلاميذ في الفصل الثانى r & $\varepsilon$ \\
\hline rᄉ & التلاميذ فن الفصل التاسع & 0 \\
\hline $1 \cdot r$ & \multicolumn{2}{|c|}{ مجموعة } \\
\hline
\end{tabular}

وتأخذ عينة البحث بطريقة العينة العشوائية البسيطة. وعينته تلاميذ من الفصل الأول، وهو ينقسم على الفصل الأول القسم الاجتماعي ا الفصل الأول القسم

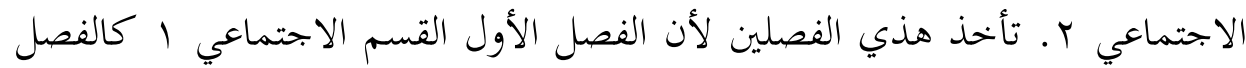

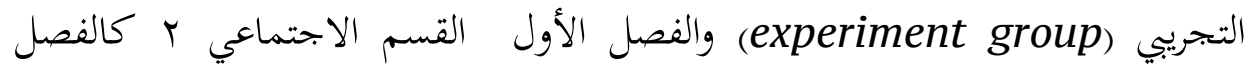
المراقبي (control group)، وهو كما يلي:

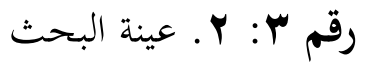

\begin{tabular}{|c|c|c|}
\hline التلاميذ & العناصر & 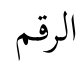 \\
\hline ri & التلاميذ في الفصل الأول 1 & 1 \\
\hline$r$. & التلاميذ في الفصل الأول r & r \\
\hline
\end{tabular}


تأثير استخدام البطاقة ... - .

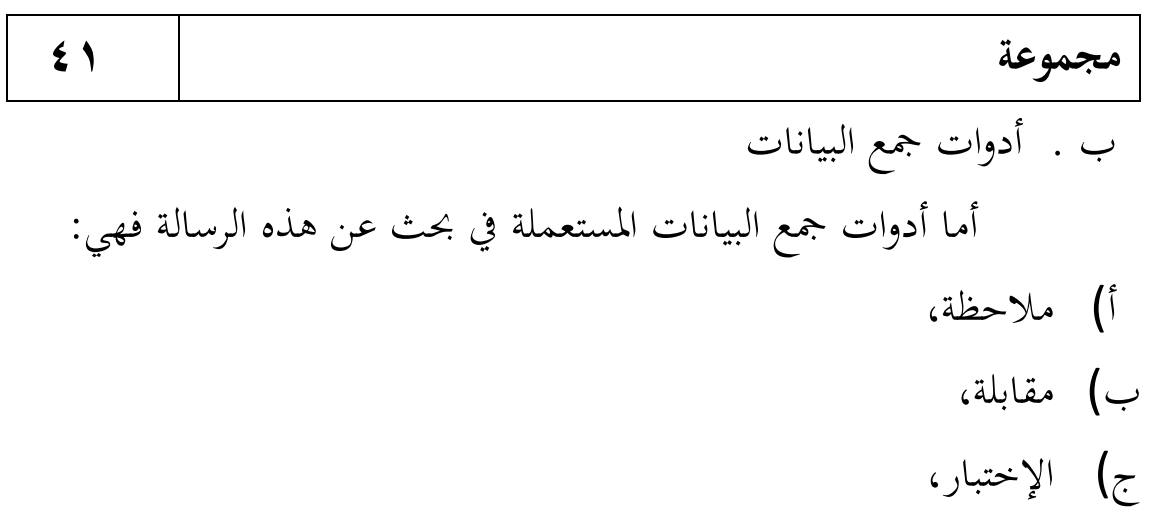

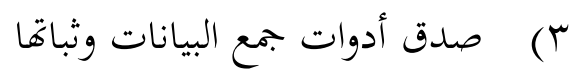
أما صدق أدوات جمع البيانات وثباها هي تقوم بالإختبار والمقابلة لمعرفة نتيجة التلاميذ في تعليم مهارة القراءة والمسائل المتعلقة بالبحث، لصدق أدوات جمع البيانات تأخذ من مصدر البحث يعنى كتاب اللغة العربية يستعملها المدرس في عملية التعليم وصنعت بانماط المقابلة، ثم إستشار سؤال الإختبار وانماط المقابلة إلى المدرس ومشرفين في كتابة الرسالة العلمية، ولا يكفى الإختبار بمرة فقط وركن مرات وعلى الأقل مرتين. أما ثبات أدوات جمع البيانات في هذا البحث فتمادى في الميدان للحصول البيانات ثم إستشار حصول البيانات إلى المدرس ومشرفين في كتابة الرسالة العلمية. ج) تصميم البخث إن تصميم بجريب للباحثة كالرسم الهندسي المعياري، فإذا جاء هذا التصميم مبهما أو غير دقيق جاءت نتائج البحث ضعيفة القيمة ومبهمة، أما التصميم الذي يجسن الباحث وضعه وصياغته فأنه يضمن الهيكل السليم والإستراتيجية المناسبة التي

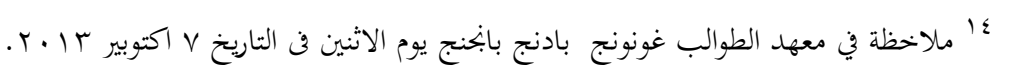


Selvia Nelis

تضبط له بحثه وتوصله إلى نتائج يمكن الإعتماد عليها في الإجابة على الأسئلة التي طرحتها مشكلة البحث وفروضه، فالتصميم يقترح على الباحث الملاحظات التي ينبغي أن يقوم بها والأسلوب الذي ينبغي أن يقوم به والأسلوب الذي ينبغي عليه أن يتبعه كما يقترح عليه الأدوات الإحصائية المناسبة وكيفية تحليل المادة التي يجمعها والنتائج المحتملة $\circ$

التي يمكن أن يستخلصها من التحليل.

وفي هذا البحث تستعمله الكاتبة تصميما، تستعمل تصميم True

الجماعة 7 هو

Eksperimental باستخدامPretest-Postest Control Group Design المتكافئة أو الموازية الاختبار القبلي والاختبار البعدي لكل من المجموعتين التجريبية والضبطبية. لأن في هذا التصميم تقومه الكاتبة بتجريبة جديدة بأي تعليم مهارة القراءة باستخدام البطاقة v

للفرقة الأولى وبغيره للفرقة الثانية، وتصور في الجدول التالى : رقم ץ: ". تصميم البحث

\begin{tabular}{|r|r|r|r|}
\hline $\mathrm{R}$ & 01 & $\mathrm{X}$ & 02 \\
\hline $\mathrm{R}$ & 01 & - & 02 \\
\hline
\end{tabular}

رحيم يونس كرو العزاوي، مرجع سابق، ص. 111)

'Moch. Ainin, Metodologi Penelitian Bahasa Arab, (Malang: Hilal Pustaka, 2007), h. 83

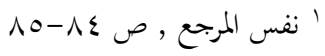


الإيضاح : R : R : الفرقة/ الفصل

01

: X

02

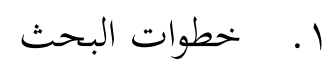

أما الخطوات فن البحث التجريبى فهو كما يلى:

أ) أ التعرف على المشكلة وتحديدها

ب). صياغة الضروض واستنباط نتائجها

ج). وضع تصميم بتربي يتضمن جميع النتائج وشروطها وعلاقتها د) د إجراء التجربة

هـ). تنظيم البيانات الخام واختصارها بطريقة تؤدي إلى أفضل تقدير غير متميز للأثر الذي يفترض وجودها

و ). تطبيق اختبار دلالة مناسب لتحديد مدى الثقة في نتائج الدراسة.

أ. أ. تحليل البيانات

في هذا البحث تعلّم الباحثة تعليم مهارة القراءة للتلاميذ من الفصل الأول الميات



“' رحيم يونس كرو العزاوي، مرجع سابق، ص. 111. 
Selvia Nelis

الأول ب بدون استخدام البطاقة ثم تقوم الإختبار لهم. وفي إهاء البيانات تستعمل الكاتبة تحليل اختبار - ت (Tes " $\mathrm{t}_{\mathrm{o}}=\underline{\mathrm{MD}}$

\section{SEMD}

$$
\begin{aligned}
\text { الإيضاح : } & \text { To } \\
\text { الاخخبار } & =\text { To }
\end{aligned}
$$

SEMD

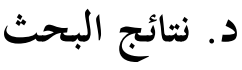

في نتيجة البحث تعرض الكاتبة تأثير استخدام البطاقة في تعليم مهارة القراءة (بحث بحريب). كانت وسيلة البطاقة التي استخدمتها الكاتبة هي قطعة البطاقة من الورق، ثم أخذات الكاتبة المادة التعليمية من الكتاب "دروس اللغة العبية ألفه أ.د. هداية" والكتاب دروس اللغة العربية في المدرسة الثانوي سمطرى غربية ومادة البحث عن "بَيْتُّ" التي تناسب بالمادة التي سيتعلّمها التلاميذ في هذا المعهد الفصل الأول في الدور الثّاني. هذه الطريقة جربتها الكاتبة الفصل التجريبي في تعليم مهارة القراءة بإقامة الاختبار القبلي (Pre-test)، العملية التجريبية، والاختبار البعدي (Post-test)، أما هذا الحال تقوم لنظرة تأثير تعليم القراءة من أربعة معاير فهي قدرة التلاميذ في نطق الأصوات، قدرة التلاميذ في نطق المفردات العبية، قدرة التلاميذ في نطق الجملة البسيطة، وفي معرفة ترقية نتيجة تعليم القراءة في المستوى الثانوي بمعهد الأيوبى بوبنو. فأقامت الكاتبة أيضا الاختبار القبلي، العملية التعليمية العادة دون التجريب، ثم الاختبار البعدي لنظرة نتيجة تعليم القراءة لهم من أربعة معاير . 


\section{تحليل البيانات في الفصل التجريبي}

كما قالت الكاتبة أن ثلاثة أهداف لتعليم القراءة في هذا البحث، يعنى في نطق الأصوات العربية وفي نطق المفردات العربية وفي نطق الجملة البسيطة، فتحلل الكاتبة بيانات بخطوات إحصائية من اختبارا- ت. وتحللها الكاتبة من نتيجة الاختبار القبلي to والاختبار البعدي (Y) (X) وإعطاء التفسير لنتيجة (X)

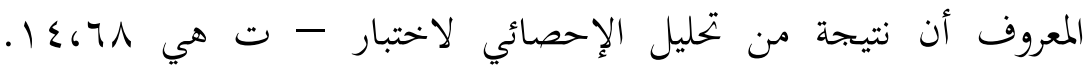

لإمتحان نتيجة لاختبار - ت to to إستشارة إلى قيمة t، كما في الجدول على الدرجة ه

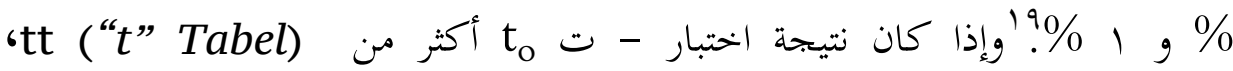
فالفرض التبادلية Alternatif (Ha) مقبولة والفرض العدمية Nihil (Ho) مردودة، وبالعكس إذا كان أقل من tt (tt" Tabel) فالفرض التبادلية مردودة، والفرض

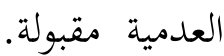

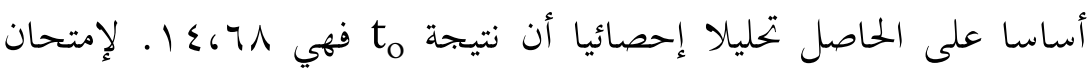

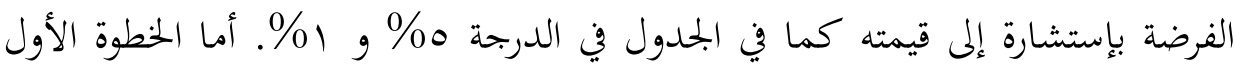
التي تستعملها الكاتبة فهي تبحث عن قيمة أو نتيجة درجة حرورية (db) بالرمز :

$$
\mathrm{db}=\mathrm{N}-1
$$

$$
\begin{aligned}
& \text { الإيضاح : db درجة حرورية db } \\
& \text { = }=\mathrm{N}
\end{aligned}
$$

'Anas Sudijono, Pengantar Statistik, h. 404. 
Selvia Nelis

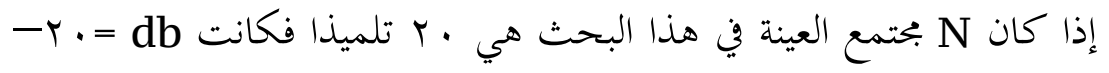

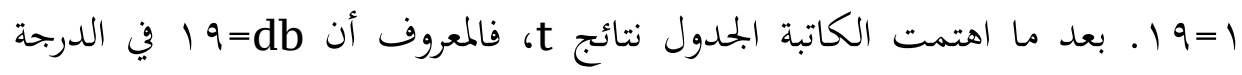

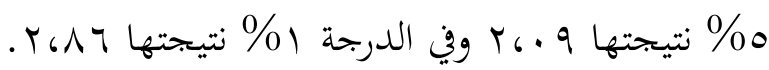

كانت نتيجة to - toدرة التلاميذ في نطق الأصوات من الفصل التجريبي-


مقبولة. إذن، توجد الكاتبة فرق بين قدرة التلاميذ في نطق الأصوات العربية قبل التعليم

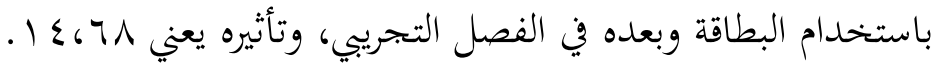
تحليل البيانات فى الفصل المراقبي كما في الفصل التجريبي أن أهدافين لتعليم القراءة في هذا البحث، هما في نطق

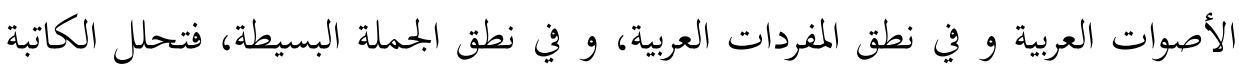
بيانات بخطوات إحصائية من اختبار - ت. وتحللها الكاتبة من نتيجة الاختبار القبلي (X) و الاختبار البعدي (Y) (X). إعطاء التفسير على النتيجة المصصولة (to)

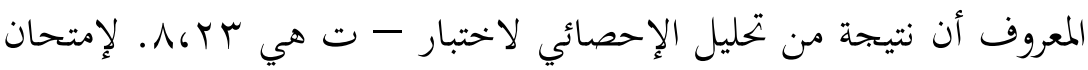

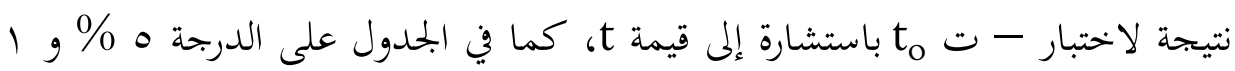

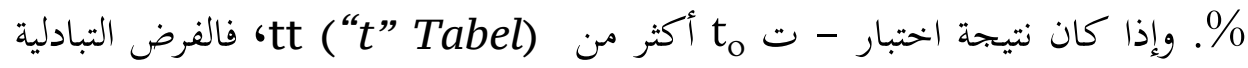
Alternatif (Ha) كان أقل من tt (t “t Tabel فالفرض التبادلية مردودة، والفرض العدمية مقبولة. 
أساسا على الحاصل تحليلا إحصائيا أن نتيجة to فهي


التي تستعملها الكاتبة فهي تبحث عن قيمة أو نتيجة درجة حرورية (db) بالرمز :

$$
\mathrm{db}=\mathrm{N}-1
$$

$$
\begin{aligned}
& \text { الإيضاح: db = dرجة حرورية } \\
& \text { = }=\mathrm{N}
\end{aligned}
$$

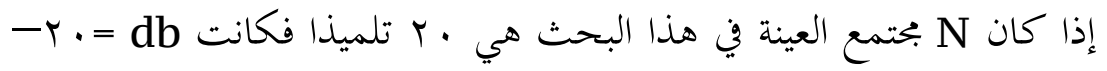

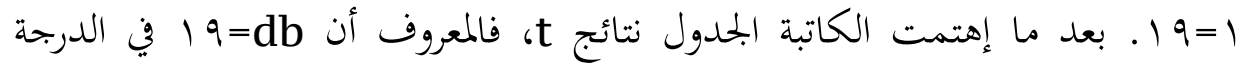

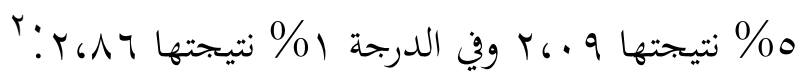
كانت نتيجة to - قدرة التلاميذ في نطق الأصوات العربية في الفصل المراقبي-

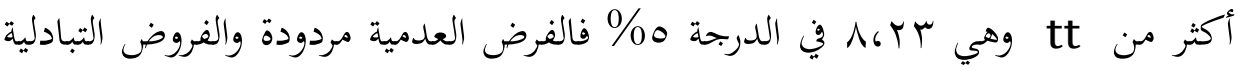
مقبولة. إذن، توجد الكاتبة فرق بين قدرة التلاميذ في نطق الأصوات من القراءة قبل

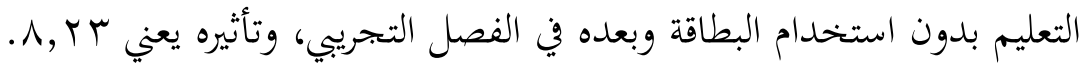
تحليل البيانات بين نتيجة الفصل التجريبي والفصل المراقبي

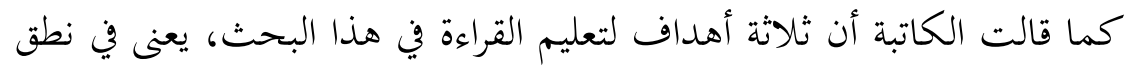
الأصوات العربية وفي نطق المفردات العربية وفي نطق الجملة البسيطة، فتحلل الكاتبة

$$
\text { r نفس المرجع }
$$


Selvia Nelis

بيانات بخطوات إحصائية من اختبارا- ت. و تحللها الكاتبة من نتيجة الاختبار القبلي

(X) و الاختبار البعدي (X)

وطريقته كما يلي:

أ) تحليل البيانات في نطق الأصوات العربية

أما خطوات إحصائية لتحليل البيانات في نطق الأصوات العربية في الفصل

التجريبي فهي باختبار - ت، كما يلي :

ا ـ تبحث الكاتبة عن فرق الدرجة بين النتيجتين باستعمال الرمز: D=X-Y

$$
\text { Y . تبحث الكاتبة عن درجة D حتى يكصل على }
$$

فوجدت الكاتبة نتائج التلاميذ من تحليل البيانات في الفصل التجريبي والفصل

المراقبي في نطق الأصوات العربية بين الاختبار القبلي والاختبار البعدي. فتصور أن عدد كله · r تلميذ (N))، والحاصل من مجموعة القيمة لقدرة التلاميذ في نطق الأصوات

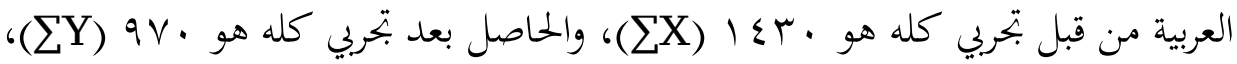
والحاصل (XD ب) تبحث الكاتبة عن معدل فرق الدرجة باستعمال الرمز :

$$
\mathrm{M}_{\mathrm{D}}=\sum \frac{\mathrm{D}}{\mathrm{N}}
$$

$$
=\frac{\varepsilon T .}{r} .
$$

$$
=r r
$$


ع) تبحث الكاتبة عن to to $\frac{\mathrm{M}_{\mathrm{D}}}{\mathrm{SE}_{\mathrm{MD}}}=\mathrm{t}_{\mathrm{o}}$

$$
\begin{aligned}
& \frac{r r}{r 619}= \\
& r_{6 r 1}=
\end{aligned}
$$

to إعطاء التفسير لنتيجة

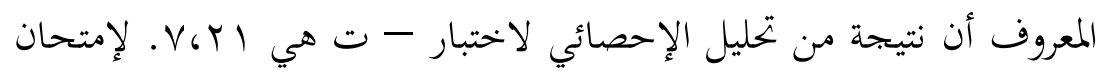

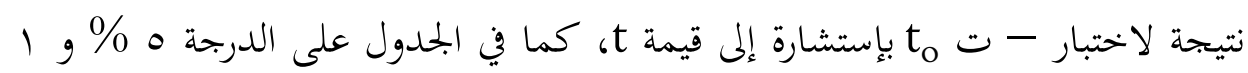

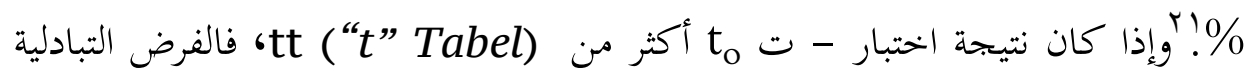
مihil (Ho) مقبولة والفرض العدمية مihornatif (Ha) كان أقل من (tt “t "Tabel فالفرض التبادلية مردودةة، والفرض العدمية مقبولة.

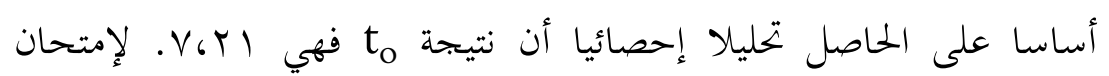
الفرضة بإستشارة إلى قيمته كما في الجدول في الدرجة ه\% و و 1\%. أما الخطوة الأول التي تستعملها الكاتبة فهي تبحث عن قيمة أو نتيجة درجة حرورية (db) بالرمز: 
Selvia Nelis

$$
\begin{aligned}
\mathrm{db}=\mathrm{N}-1 & \\
\text { الإيضاح } & \text { = db }=\mathrm{N} \\
&
\end{aligned}
$$

إذا كان N بحتمع العينة في هذا البحث هي · ب تلميذا فكانت db =. r19=1 ا . بعد ما اهتمت الكاتبة الجدول نتائج t، فالمعروف أن db=db 19 في الدرجة

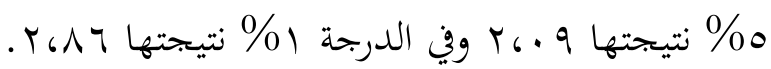

كانت نتيجة to -قدرة التلاميذ في نطق الأصوات العربية من الفصل التجريبي- أكثر من tt وهي الT، It في الدرجة هo\% فالفرض العدمية مردودة والفروض التبادلية مقبولة. إذن، توجد الكاتبة فرق بين قدرة التلاميذ في نطق الأصوات العربية من مهارة القراءة قبل التعليم باستخدام البطاقة وبعده في الفصل التجريبي، وتأثيره يعني . VGY

$$
\text { ب) تحليل البيانات في نطق المفردات العربية }
$$

أما خطوات إحصائية لتحليل البيانات في نطق المفردات العربية في الفصل

$$
\text { التجريبي فهي باختبار - ت ت، كما يلي: }
$$

( ) Dبحث الكاتبة عن فرق الدرجة بين النتيجتين باستعمال الرمز: D=X-Y

$$
\text { Y }
$$

فوجدت الكاتبة نتائج التلاميذ من تحليل البيانات في الفصل التجريبي والفصل المراقبي في نطق المفردات العربية بين الاختبار القبلي والاختبار البعدي. فتصور أن عدد 
كله · r تلميذ (N)، والحاصل من بحموعة القيمة لقدرة التلاميذ في نطق الأصوات

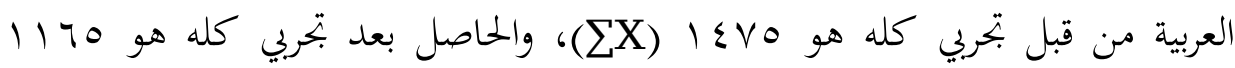

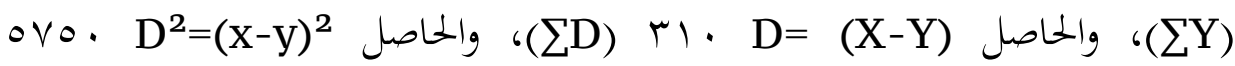
$\cdot\left(\sum \mathrm{D}^{2}\right)$

r $\mathrm{M}_{\mathrm{D}}=\sum \frac{\mathrm{D}}{\mathrm{N}}$

$$
\begin{aligned}
& \frac{=r \cdot}{r} \\
& =1060
\end{aligned}
$$

ع) تبحث الكاتبة عن to باستعمال الرمز : $\frac{\mathrm{M}_{\mathrm{D}}}{\mathrm{SE}_{\mathrm{MD}}}=\mathrm{t}_{\mathrm{o}}$

$$
\begin{aligned}
& \frac{1060}{160 \mathrm{~V}}= \\
& 96 \mathrm{NV}=
\end{aligned}
$$

o) إعطاء التفسير لنتيجة to

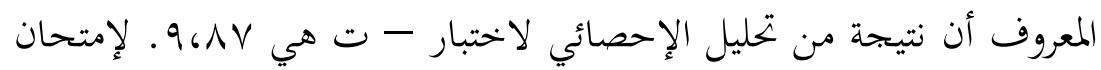

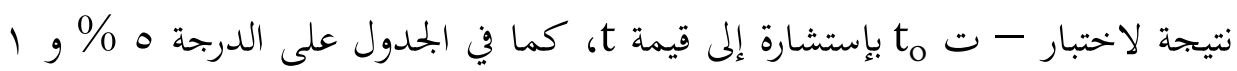




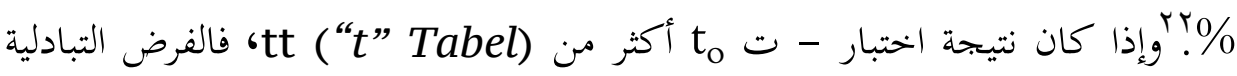

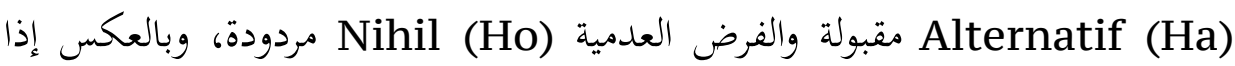
كان أقل من (tt (t) فالفرض التبادلية مردودة، والفرض العدمية مقبولة.

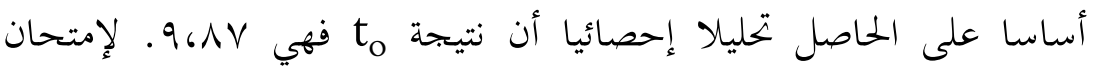

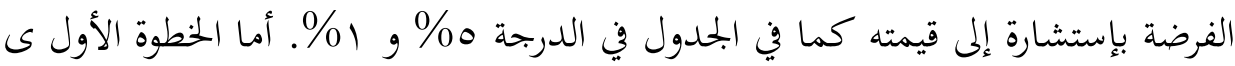
التي تستعملها الكاتبة فهي تبحث عن قيمة أو نتيجة درجة حرورية (db) بالرمز :

$$
\begin{aligned}
& \mathrm{db}=\mathrm{N}-1 \\
& \text { الإيضاح: db = d = درجة حرورية } \\
& \text { = }=\mathrm{N}
\end{aligned}
$$

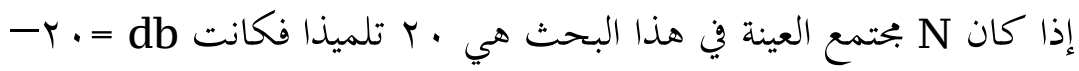

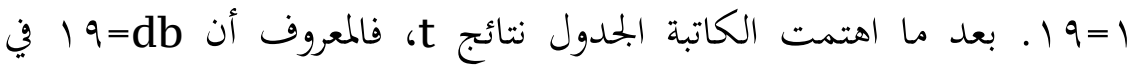

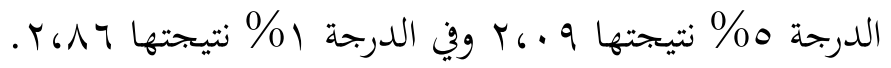

كانت نتيجة to -قدرة التلاميذ في نطق المفردات من الفصل التجريبي- أكثر من tt وهي Av و، في الدرجة ه\% فالفرض العدمية مردودة والفروض التبادلية مقبولة. إذن، توجد الكاتبة فرق بين قدرة التلاميذ في نطق المفردات من مهارة القراء قبل التعليم

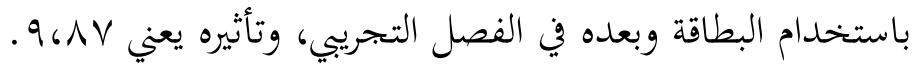
ج) تحليل البيانات في نطق الجملة البسيطة

$$
\text { r }
$$


أما خطوات إحصائية لتحليل البيانات في نطق الجملة البسيطة في الفصل

$$
\begin{aligned}
& \text { التجريبي فهي باختبار - ت، كما يلي: } \\
& \text { ( ) تبحث الكاتبة عن فرق الدرجة بين النتيجتين باستعمال الرمز: D=X-Y }
\end{aligned}
$$

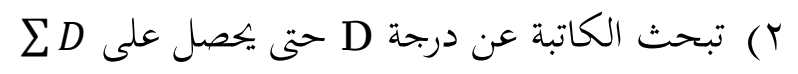

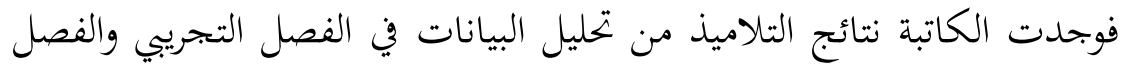

المراقبي في نطق الجملة البسيطة بين الاختبار القبلي والاختبار البعدي. فتصور أن عدد كله · r تلميذ (N)، والحاصل من بحموعة القيمة لقدرة التلاميذ في نطق الأصوات

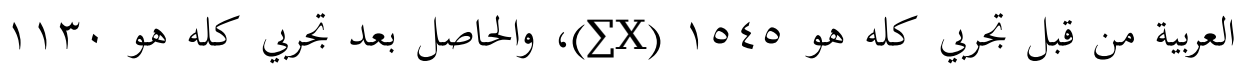
q1V0 $\mathrm{D}^{2}=(\mathrm{X}-\mathrm{y})^{2}$ والحركل $\cdot\left(\sum \mathrm{D}^{2}\right)$

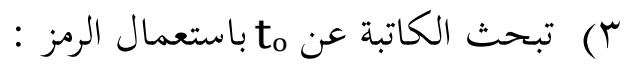

$$
\begin{aligned}
\frac{\underline{M}_{D}}{S E_{M D}} & =t_{0} \\
\frac{r \cdot 6 V_{0}}{16 r r} & = \\
1 V_{6} \cdot 1 & =
\end{aligned}
$$

؟ ) إعطاء التفسير لنتيجة to

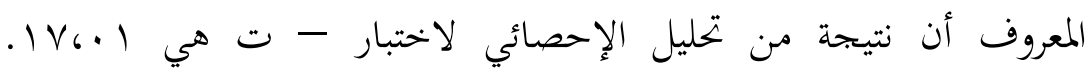

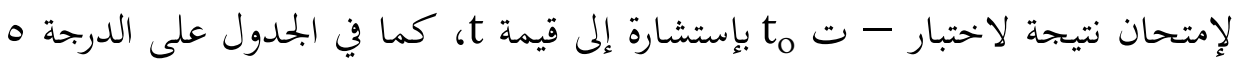


Selvia Nelis

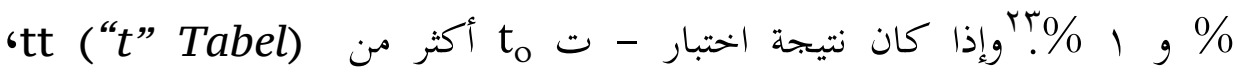
فالفرض التبادلية Alternatif (Ha) مقبولة والفرض العدمية Nihil (Ho) مردودة، وبالعكس إذا كان أقل من tt "tt"Tabel فالفرض التبادلية مردودة، والفرض العدمية مقبولة.

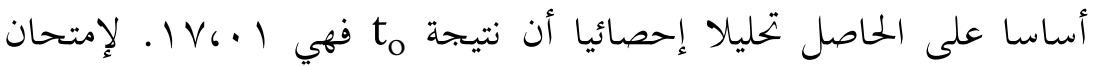
الفرضة بإستشارة إلى قيمته كما في الجدول في الدرجة ه\% و 1\% أما ألخطوة الأول التي تستعملها الكاتبة فهي تبحث عن قيمة أو نتيجة درجة حرورية (db) بالرمز :

$$
\mathrm{db}=\mathrm{N}-1
$$

$$
\begin{aligned}
& \text { الإيضاح : db = درجة حرورية } \\
& \text { = }=\mathrm{N}
\end{aligned}
$$

إذا كان N بحتمع العينة في هذا البحث هي · ب تلميذا فكانت db =. r19=1 ا . بعد ما اهتمت الكاتبة الجدول نتائج t، فالمعروف أن db=db 1 في الدرجة

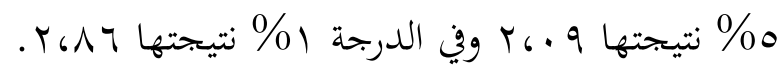

كانت نتيجة to - مقرة التلاميذ في نطق الجملة البسيطة من الفصل

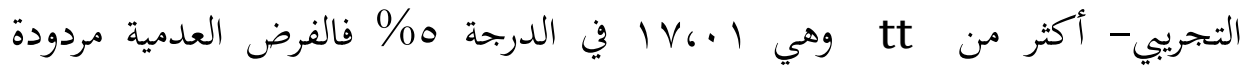
والفروض التبادلية مقبولة. إذن، توجد الكاتبة فرق بين قدرة التلاميذ في نطق الجملة 
البسيطة من مهارة القراءة قبل التعليم باستخدام البطاقة وبعده في الفصل التجريبي،

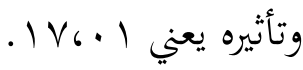
هـ الخلاصة أما خحلاصة من البحث السابق فهي ما يلي : البحل 1 ـ النتيجة المحصولة في الفصل التجريبي أن وسيلة البطاقة لها أثار على قدرة التلاميذ في

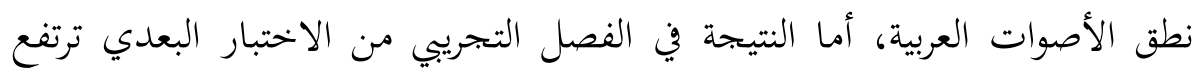

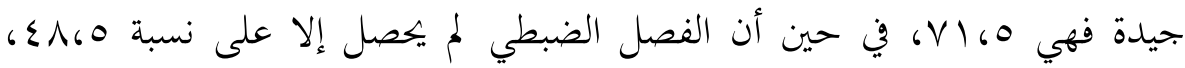

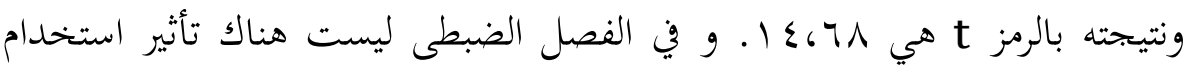
البطاقة على قدرة التلاميذ في نطق الأصوات العربية في هذا المعهد. والنتيجة المحصولة

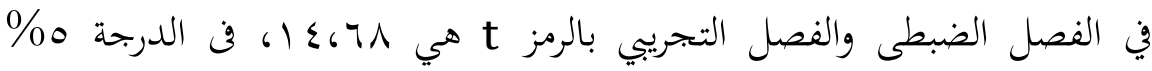

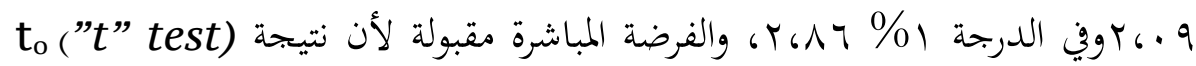

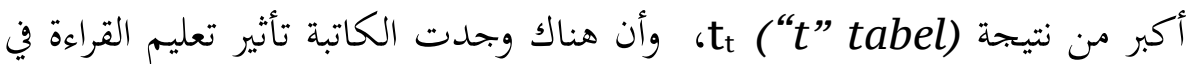
نطق الأصوات العربية باستخدام البطاقة. r. النتيجة المحصولة في الفصل التجريبي أن وسيلة البطاقة لما أثار على قدرة التلاميذ في نطق المفردات العربية، أما النتيجة في الفصل التجريبي من الاختبار البعدي ترتفع

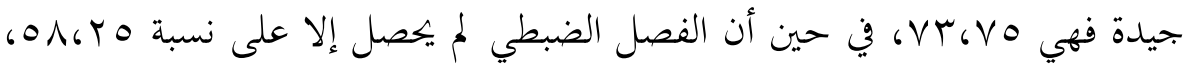

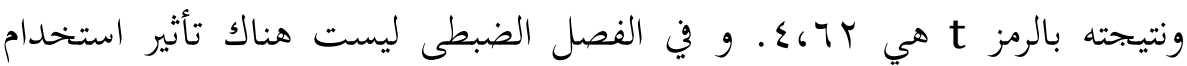
البطاقة على قدرة التلاميذ في نطق المفردات العربية في هذا المعهد. والنتيجة المحصولة

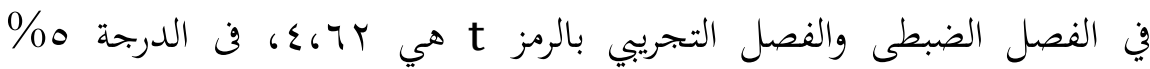


Selvia Nelis

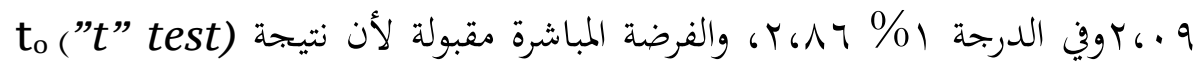

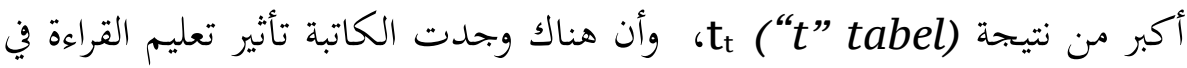
نطق المفردات العربية باستخدام البطاقة. ب. النتيجة المحصولة في الفصل التجريبي أن وسيلة البطاقة لما أثار على قدرة التلاميذ في نطق الجملة البسيطة، أما النتيجة في الفصل التجريبي من الاختبار البعدي ترتفع



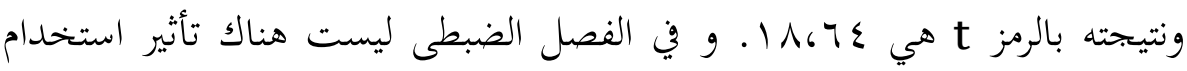
البطاقة على قدرة التلاميذ في نطق الجملة البسيطة في هذا المعهد. والنتيجة المحصولة

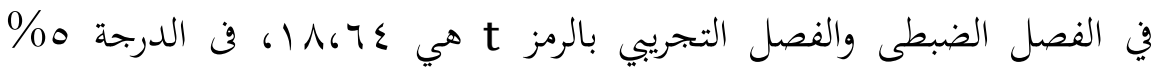

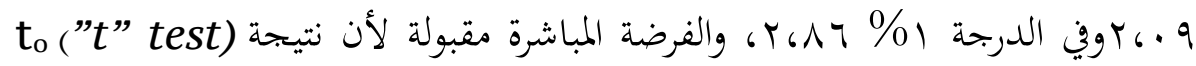

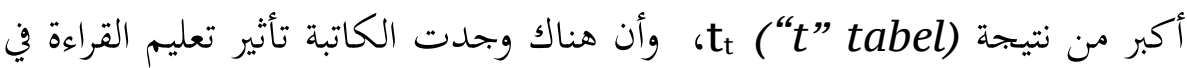
نطق الجملة البسيطة بااستخدام البطاقة.

اذن, وسيلة البطاقة لما أثنار في تعليم القراءة إما قدرة التلاميذ في نطق الأصوات العربية، المفردات العربية وفي نطق الجملة البسيطة باستخدام البطاقة. و يؤثر على ترقية نتيجة في تعليم القراءة، وهذا يستدل على النتيجة التي يوجدها التلاميذ من الفصل الضبطي والفصل التجريبي. 


\section{المراجع}


أحمد فؤاد عليان، المهارات اللغوية ماهيتها وطرائق تنميتها، الرياض: دار المسلم، . r...

أوريل بحرالدين، مهارات التدريس نحو إعداد مدرس اللغة العربية الكفء، مالانج:

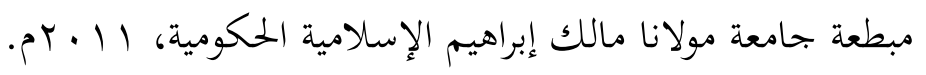

جاسم محمود الحسون وحسن جعفر الخليفة، طرق تعليم اللغة العربية في التعليم العام دم: جامعة عمر المختار، 991 ام.

جودت الركابي، طرق تدريس اللغة العربية، سورية: دار الفكر: 1997

رشدي أحمد طعيمة، دليل عمل في اعداد المواد التعليمية لبرامج تعليم العربية، المكة

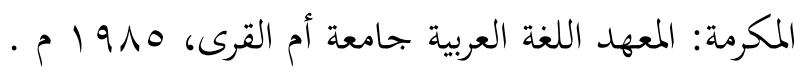

زين العارفين، اللغة العربية طرائق تعليمها وتعلمها، بادنج: مطبعة حيف، · ب ب فتحى على يونس ومحمد عبد الرؤوف الشيخ، المرجع في تعليم اللغة العربية

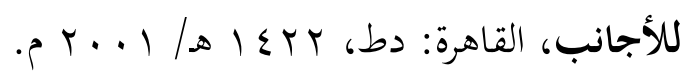

فتحى على يونس ومحمود كامل لناقة، أساسيات تعليم اللغة العربية والتربية الدينية،

$$
\text { (القاهرة: جامعة عمر المختار، د.س وسى }
$$


Selvia Nelis

عبد الحليم حنفي، طرق تعليم اللغة العربية، باتوسنكر:0 . . بم • عبد الرحمن بن ابراهيم الفوزان، اعداد مواد تعليم اللغة العربية لغير الناطقين بها، القاهرة: دار الفكر، د. س

عبد العليم إبراهيم، الموجه الفنى لمدرسي اللغة العربية، مصر: دار المعارف، 111 11 عبد الرحمن بن إبراهيم الفوزان, إضاءات لمعلمى اللغة العربية لغير الناطقين بها,

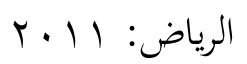

صلاح عبد البحيد العربي، تعلّم اللغات الحية وتعليمها بين النظرية والتطبيق، القاهرة: مكتبة لبنان, د. س

محمد على الكامل، الموجة لتعليم المهارات اللغوية لغير النطقين بها، سودان: جامعة

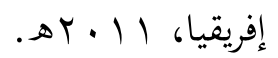

محمد عبد القادر أحمد، طرق تعليم اللغة العبية، القاهرة: دط، ع 9 ا ا م. حمود اسماعيل صيني، دليل المعلم إلى استخدام الصور والبطاقات في تعليم العربية، الرياض: مكتب التربية لدول الخليج، 999 |م.

محمد على السمان، التوجيه فى تدريس اللغة العربية، مصر: دتر المعارف، سمو ام. محمد عبد الخالق محمد، اختبارات اللغة، الرياض: جامعة الملك سعود، إع اهـ 
مصطفى عبد العزيز ، الألعاب الغوية في تعليم اللغات الأجنبية الرياض : دار

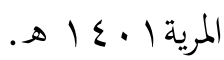

Abdul Halim Hanafi, Perencanaan Sistem Pengajaran Bahasa Arab, Batusangkar: STAIN Batusngkar, 2003 Abdul Halim Hanafi, Bimbingan Metodologi Riset dan Penulisan Karya Ilmiah, Batusangkar :STAIN Batusangkar Press, 2008

Anas Sudijjono, Pengantar Statistik Pendidikan, Jakarta:

PT Raja Grafindo Persada, 1994

M.Ainin, dkk, Evaluasi dalam Pembelajaran Bahasa Arab, Malang: Misykat, 2006

M. Ainin, Metodologi Penelitian Bahasa Arab, (Malang: Hilal Pustaka, 2007 